Research Article

Genetics of Microorganisms

\title{
Genome sequencing and analysis of plant growth-promoting attributes from Leclercia adecarboxylata
}

\author{
Aline Snak ${ }^{1}$, Eliane Cristina Gruszka Vendruscolo ${ }^{1}$ (D), Marise Fonseca dos Santos ${ }^{1}$, \\ Adriana Fiorini ${ }^{1,2}$ and Dany Mesa ${ }^{3}$ \\ ${ }^{1}$ Universidade Federal do Paraná, Labiogen-Laboratório de Bioquímica e Genética, Palotina, PR, Brazil. \\ ${ }^{2}$ Universidade Federal do Paraná, Departamento de Biociências, Palotina, PR, Brazil. \\ ${ }^{3}$ Universidade Federal do Paraná, Departamento de Bioquímica, Centro Politécnico, Jardim das Américas, \\ Curitiba, PR, Brazil.
}

\begin{abstract}
Plant growth-promoting bacteria are ecological alternatives for fertilization, mainly for gramineous. Since plant $x$ bacteria interaction is genotype and strain dependent, searching for new strains may contribute to the development of new biofertilizers. We aim to characterize plant growth-promoting capacity of Leclercia adecarboxylata strain Palotina, formerly isolated by our group in corn. A single isolated colony was taken and its genome was sequenced using Illumina technology. The whole genome was compared to other Leclercia adecarboxylata strains, and their biological and growth-promoting traits, such as $\mathrm{P}$ solubilization and auxin production, were tested. Following that, a $4.8 \mathrm{Mb}$ genome of $L$. adecarboxylata strain Palotina was assembled and the functional annotation was carried out. This paper is the first to report the genes associated with plant growth promotion demonstrating in vitro indole acid production by this strain. These results project the endophyte as a potential biofertilizer for further commercial exploitation.
\end{abstract}

Keywords: Endophyte, Leclercia, genome, plant growth promotion, strains.

Received: April 24, 2020; Accepted: December 11, 2020

\section{Introduction}

Leclercia adecarboxylata, a member of the Enterobacteriaceae family, is a motile, aerobic, omnipresent Gram-negative bacterium. Infections by $L$. adecarboxylata in humans are scarcely reported, being considered an opportunistic pathogen (Kashani et al., 2014; Hoyos-Mallecot et al., 2017; Choudhary et al., 2018). This strain was first described and named Escherichia adecarboxylata by Leclerc (1962), and, later received the generic name Leclercia from Tamura et al., (1986). It was phenotypically differentiated by biochemical and DNA hybridization assays from other Enterobacteriaceae species (Choudhary et al., 2018). Recently, Hoyos-Mallecot et al. (2017) published the draft genome of L. adecarboxylata strain harboring an NDM1 (Multidrug-resistant New Delhi metallo- $\beta$-lactamase 1) gene.

Plants and microorganisms naturally interact in the soil, forming a narrow and complex communication network. This network operates on biochemical to molecular signals, which can be altered according to the type of association (Souza et al., 2015). The promotion of direct growth occurs through the availability of nutrients, nitrogen, phosphate, as well as the production of plant regulators as auxins, cytokinins and amino acids. These regulators mainly promote central and lateral root growth, increasing the absorption surface, which in turn increases the root's nutrient and water uptake (Beneduzi et al., 2012; Jha and Saraf, 2015).

Send correspondence to Eliane Cristina Gruszka Vendruscolo. Universidade Federal do Paraná, Labiogen-Laboratório de Bioquímica e Genética, Rua Pioneiro, 2153, CEP: 85950-000, Palotina, PR, Brazil. E-mail: egvendru@gmail.com.
However, the promotion of indirect growth occurs by means of induced systemic resistance (ISR). Some biocontrol mechanisms of pathogens are antibiosis, parasitism, competition for nutrients, production of hydrogen cyanide, siderophores, including the ones involved in responses to abiotic stresses, such as drought, salinity, extreme temperatures (Moreira et al., 2016).

Although this organism has been reported globally in food, water and animals (Tamura et al., 1986; Anuradha, 2014), for instance in strawberry root (Laili et al., 2017), evidences of its efficiency as plant growth promoter bacteria is scarce. In this context, we sequenced the complete genome of Leclercia adecarboxylata strain Palotina carrying out a comparative analysis with genomes of 16 different strains. This study provides new insights into genetic determinants, and as such may clarify some reported metabolic abilities of the Palotina strain, offering basic information on genetic plant growth promotion that may be relevant for biotechnological interest.

\section{Material and Methods}

\section{DNA extraction and sequencing}

Genomic DNA was extracted from the isolated strain following the protocol by Souza et al. (1991), using as template for a PCR reaction, $\mathrm{Y} 1$ and $\mathrm{Y} 3$ primers for amplification of the 16S rRNA gene (Cruz et al., 2001). Amplicons were enzymatically treated with ExoI/SA and the sequencing was performed on BigDye ${ }^{\circledR}$ Terminator v3.1 Cycle Sequencing in an ABI3500xL. The resulting sequences were assembled with CAP3 using BLASTn for comparison at NCBI. 
The gDNA of Leclercia was quantified with Qubit, diluted and used for the construction of genomic DNA sequencing libraries using Illumina NexteraXT kit, according to the manufacturer's recommendations. The libraries were quantified and the quality was verified by means of Bioanalyzer. The libraries were diluted to $500 \mathrm{pM}$ and pooled. This pool was quantified by qPCR using the Kapa Biosystems kit, and $17.5 \mathrm{pM}$ of pooled libraries were sequenced in the Illumina MiSeq with $500 \mathrm{~V} 2 \mathrm{kit}$ in paired-end, generating paired reads of 250 base pairs from DNA fragments.

\section{Genome assembly, annotation and serotyping}

Overall, 5,795,728 reads were generated, representing a 31-fold coverage for the strain Palotina. FastQC (www. bioinformatics.babraham.ac.uk/projects/fastqc/) was used to check the quality of the reads. SPAdes program (Bankevich et al., 2012), version 3.11.1 was used to reassemble the sequence dataset, which were deposited at NCBI site under the BioSample access number SAMN09791487. In order to identify putative coding sequences (CDS) and provide an initial automatic annotation, the genome sequences were submitted to the RAST server annotation pipeline (Aziz et al., 2008) and Artemis (Sanger Institute, Cambridge, UK) was used to curate annotations manually.

\section{Comparative genomics}

BLAST Ring Image Generator (BRIG) program (Alikhan et al., 2011) was used to compare the genome of L. adecarboxylata strain Palotina at nucleotide level against other strains available in the NCBI site (Table 1). It uses the Basic Local Alignment Search Tool (BLAST) (Altschul et al., 1990), which is considered the most common tool for comparing genomes. Only 16 complete genomes found at NCBI were considered, being 9 from $L$ adecarboxylata strains (NCTC13032; Z96-1; E61; P12375; J656; 16005813; USDAARS-USMARC-60222; E1 and R25) and 7 from Leclercia sp. strains (W6; 119287; 1106151; LSNH1; LSNH3; J807 and W17), the great majority from clinical isolates (Table 1).

Also, three genes related to plant growth promotion (P metabolism and auxins biosynthesis) were selected and compared by BLASTn against all genomes. In phylogenetic analyses, a Neighbor-Joining tree (Saitou and Nei, 1987) was constructed with 98 genomes with NCBI Tree Viewer (version 1.17.5).

\section{Biochemical characterization of $L$. adecarboxylata}

At first, L. adecarboxylata strain Palotina was isolated in LB medium, growing well in DYGS (Dobereiner et al., 1995), following the isolation protocol by (Chaves et al., 2019).

Table 1 - Characteristics of Leclercia strains used in the genomic comparison.

\begin{tabular}{|c|c|c|c|c|c|c|c|}
\hline Organism & Strain & BioSample & Assembly & Size $(\mathrm{Mb})$ & $\mathrm{GC} \%$ & Replicons & Isolation source \\
\hline $\begin{array}{l}\text { Leclercia } \\
\text { adecarboxylata }\end{array}$ & NCTC13032 & SAMEA2580321 & GCA_901472455.1 & 5.06 & 55.5 & Chromosome & Drinking water \\
\hline $\begin{array}{l}\text { Leclercia } \\
\text { adecarboxylata }\end{array}$ & Z96-1 & SAMN11950933 & GCA_006171285.1 & 5.76 & 55.4 & $\begin{array}{c}\text { Chromosome }+7 \\
\text { plasmids }\end{array}$ & Human stool \\
\hline $\begin{array}{l}\text { Leclercia } \\
\text { adecarboxylata }\end{array}$ & E61 & SAMN12289350 & GCA_008931385.1 & 5.69 & 55.0 & $\begin{array}{l}\text { Chromosome }+5 \\
\text { plasmids }\end{array}$ & Shower \\
\hline $\begin{array}{l}\text { Leclercia } \\
\text { adecarboxylata }\end{array}$ & P12375 & SAMN13341565 & GCA_009720165.1 & 4.93 & 55.6 & Chromosome & Hospital \\
\hline $\begin{array}{l}\text { Leclercia } \\
\text { adecarboxylata }\end{array}$ & $\mathrm{J} 656$ & SAMN12530229 & GCA_008807335.1 & 4.84 & 55.6 & Chromosome & Human secretion \\
\hline $\begin{array}{l}\text { Leclercia } \\
\text { adecarboxylata }\end{array}$ & 16005813 & SAMN10923138 & GCA_004295325.1 & 4.82 & 55.7 & Chromosome & Sputum \\
\hline $\begin{array}{l}\text { Leclercia } \\
\text { adecarboxylata }\end{array}$ & $\begin{array}{l}\text { USDA-ARS- } \\
\text { USMARC-60222 }\end{array}$ & SAMN04158503 & GCA_001518835.1 & 4.80 & 55.8 & Chromosome & Calf nasopharynx \\
\hline $\begin{array}{l}\text { Leclercia } \\
\text { adecarboxylata }\end{array}$ & E1 & SAMN12289304 & GCA_008931445.1 & 5.51 & 54.8 & $\begin{array}{l}\text { Chromosome }+6 \\
\text { plasmids }\end{array}$ & Shower \\
\hline $\begin{array}{l}\text { Leclercia } \\
\text { adecarboxylata }\end{array}$ & $\mathrm{R} 25$ & SAMN10790527 & GCA_006874705.1 & 4.91 & 56.2 & $\begin{array}{l}\text { Chromosome }+2 \\
\text { plasmids }\end{array}$ & Rabbit \\
\hline Leclercia sp. & W6 & SAMN09667310 & GCA_003336345.1 & 4.95 & 55.9 & Chromosome & Human stomach \\
\hline Leclercia sp. & 119287 & SAMN13394079 & GCA_009734485.1 & 4.87 & 55.6 & Chromosome & Hospital \\
\hline Leclercia sp. & 1106151 & SAMN13394552 & GCA_009740165.1 & 4.85 & 56.1 & Chromosome & Urine \\
\hline Leclercia sp. & LSNIH1 & SAMN06040403 & GCA_002902985.1 & 5.41 & 55.5 & $\begin{array}{l}\text { Chromosome }+4 \\
\text { plasmids }\end{array}$ & Sludge \\
\hline Leclercia sp. & LSNIH3 & SAMN06040408 & GCA_002935105.1 & 5.39 & 55.3 & $\begin{array}{l}\text { Chromosome }+4 \\
\text { plasmids }\end{array}$ & Sludge \\
\hline Leclercia sp. & J807 & SAMN13393390 & GCA_009734465.1 & 4.72 & 56.1 & Chromosome & Human blood \\
\hline Leclercia sp. & W17 & SAMN09667311 & GCA_003336325.1 & 5.13 & 56.0 & $\begin{array}{l}\text { Chromosome }+2 \\
\text { plasmids }\end{array}$ & Human stomach \\
\hline
\end{tabular}


Visual assays determined bacteria morphology and colony color. Bacterial phosphate solubilization was detected in vitro by inoculation in NBRIP medium (Nautiyal et al., 2000). A bacterial colony was collected with a toothpick, and each $1 / 4$ plate of NBRIP medium plate was inoculated. A halo around the colonies was observed after 10 days in a culture incubated at $28{ }^{\circ} \mathrm{C}$. The solubilization index (SI) was calculated as: $\mathrm{SI}=$ Diameter of Halo $(\mathrm{mm}) /$ Diameter of colony (mm) (Nautiyal, 1999).

Indole-3-acetic acid (IAA) production by bacteria was based on the Glickmann and Dessaux (1995) protocol. Isolates were inoculated into glass vials (penicillin-type) containing $4 \mathrm{~mL}$ of medium with tryptophan $\left(5.0\right.$ g.L $\mathrm{L}^{-1}$ glucose, 0.025 g. $\mathrm{L}^{-1}$ yeast extract and 0.204 g.L. $\left.\mathrm{L}^{-1} \mathrm{~L}-\mathrm{TRP}\right)$ and no tryptophan supplementation (Sarwar and Kremer, 1995). Triplicate vials were incubated in a shaker cooled at $28^{\circ} \mathrm{C}$ in the dark at 120 $\mathrm{rpm}$. After the growth, which occurred in $48 \mathrm{~h}, 2 \mathrm{~mL}$ of the culture medium was centrifuged at $10000 \mathrm{~g}$ for $10 \mathrm{~min}$ at 4 ${ }^{\circ} \mathrm{C}$. Next, $1 \mathrm{~mL}$ of the bacterial suspension supernatant was transferred to a $15 \mathrm{~mL}$ Falcon-type tube with the addition of $1 \mathrm{~mL}$ of Salkowski reagent. The standard curve was assayed for final concentrations of 0 to $0.03 \mathrm{mg} \mathrm{mL}^{-1}$. Samples were left in the dark for $30 \mathrm{~min}$ and the AIA quantification was performed by spectrophotometer reading at $535 \mathrm{~nm}$.

L. adecarboxylata was primarily screened and further grown on $\mathrm{LB}$ plate containing $1 \%, 2 \%, 5 \%$ and $10 \% \mathrm{NaCl}$ separately for $48 \mathrm{~h}$ at $30^{\circ} \mathrm{C}$. In addition, the optimum $\mathrm{pH}$ was checked using LB liquid medium with different $\mathrm{pH}(4 ; 5 ; 5.5$; $6 ; 6.5 ; 7 ; 7.5$ and 8 ). The growth temperatures assessed were 25 and $37^{\circ} \mathrm{C}$. The presence of oxidase was tested using TEMED $1 \%$ (N-N-dimetil-p-phenilenediamine) (Kovacks, 1956). The presence of catalase was verified by the presence of bubbles when hydrogen peroxide was deposited in a colony (Yano et al., 1991). All assays were made in triplicate.

Blood agar plates $(5 \%(\mathrm{v} / \mathrm{v})$ sheep blood) were used for biosafety test (Russell et al., 2006; Suleman et al., 2018). The hemolytic capacity was evaluated after $48 \mathrm{~h}$ from fresh culture of $L$. adecarboxylata streaked onto blood agar plates and incubated at $37 \pm 2{ }^{\circ} \mathrm{C}$.

\section{Results}

\section{Genome assembly, annotation and comparative genomics}

After de novo assembly, the genome of Leclercia adecarboxylata strain Palotina was represented in 20 contigs, sized 4,801,735 bp, with GC content of 55.7\%, 4.379 coding sequences and no plasmid were observed. The comparison showed differences in the genome of $L$. adecarboxylata strain Palotina (Figure 1, Table 1). The size of L. adecarboxylata strains ranged from 4.72 to $5.76 \mathrm{Mb}$, their $\mathrm{CG}$ content between $55-56 \%$ CG content. Some contained plasmids (up to 7).

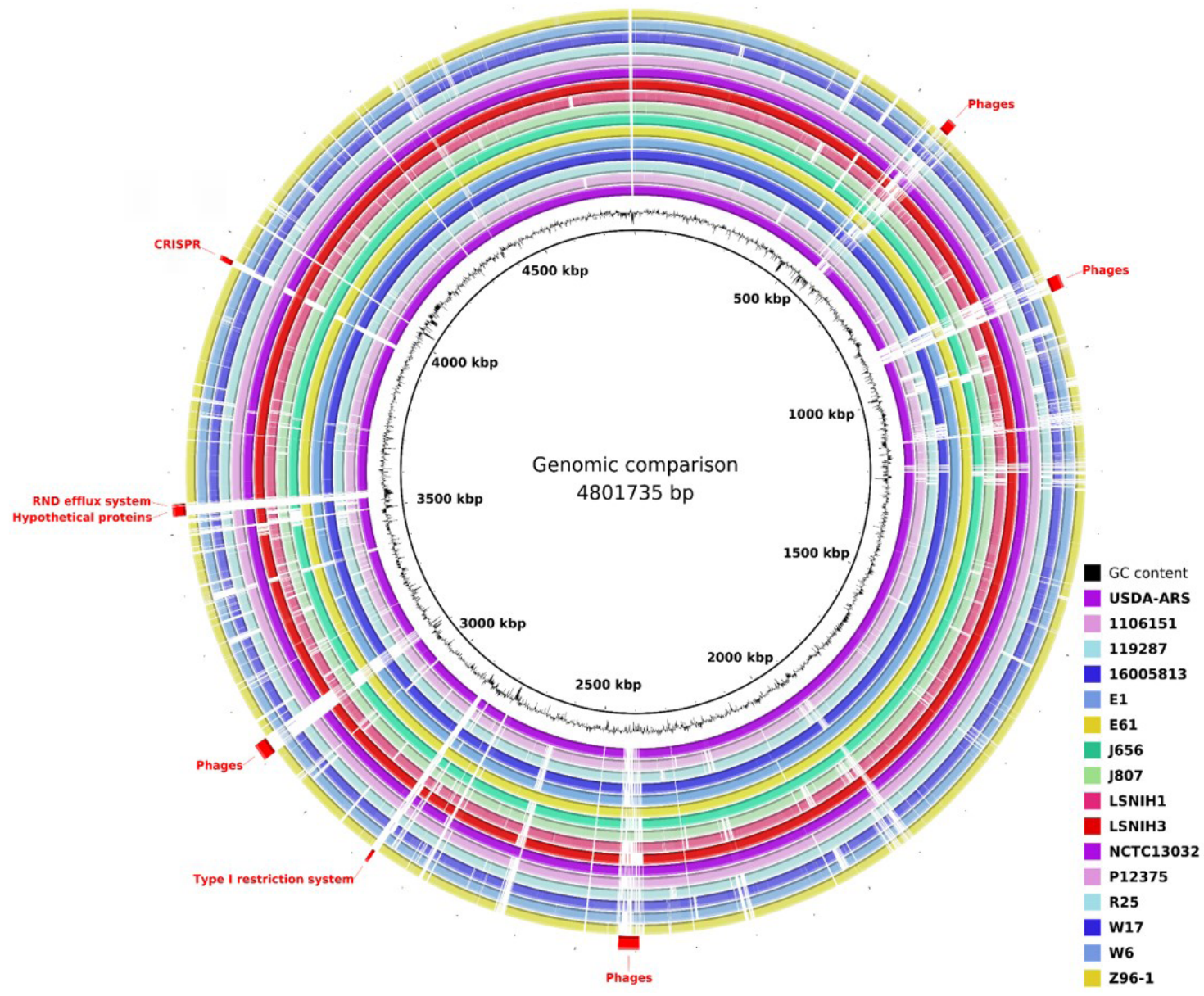

Figure 1 - Genomic comparison among Leclercia strains. Each ring represents the genome of one strain. Leclercia adecarboxylata strain Palotina (NCBI BioSample SAMN09791487) was used as genome of reference. Gaps in the rings mean absence of the region in the target genome. 
The BRIG genomic analyses showed CRISPR system and mobile elements as phages were absent in some strains. One interesting data is that no Leclercia sp contained the indole acetamide hydrolase gene. However, group genes related to bacterial systems, such as several hypothetical proteins, Type I restriction and cobalt/cadmium/zinc RND efflux, were absent in all strains used in the comparison (Figure 1, Figures S1 to S3).

Of all identified coding sequences, Rast server classified 2597 genes (60\%) in categories (Subsystems) and 1782 $(40 \%)$ were grouped as not classified (Not in Subsystems). The categories with the highest number of genes were carbohydrates metabolism (613 genes), followed by amino acids and derivatives ( 470 genes), and protein metabolism with 302 genes (Figure 2). Dormancy, sporulation and secondary metabolism showed the lowest gene number (only 5).

In addition, in the nitrogen metabolism category 49 genes were identified and then grouped in four subcategories: nitrosative stress (6 genes), nitrate and nitrite ammonification (22 genes), Ammonia assimilation (13 genes) and denitrifying reductase gene clusters with 8 genes. Phosphorus metabolism (47 genes) had 8 genes related to PHO regulon and high affinity phosphate transporter, Phosphate metabolism (22), Polyphosphate (3) and Alkylphosphonate utilization (14). Finally, in secondary metabolism 5 genes were related to Auxin biosynthesis (Table S1).

BLASTp comparison revealed 14 genes related to plant growth promotion that showed high identity ( $>97 \%$ ) and high e-value (Table S2). The phylogenetic analysis of all the 98 genomes found at NCBI, belonging to "Leclercia", showed a higher similarity between $L$. adecarboxylata strain Palotina and USDA-ARS-USMARC-60222, isolated from calf nasopharynx, an indicative that these bacteria can be associated to agricultural area, unlike clinical strains (Figure 3).

\section{Biochemical and molecular characterization of $L$. adecarboxylata}

The biological and plant growth promotion traits are summarized in Table 2. L. adecarboxylata strain Palotina is a cream rod-shaped, non-spore-forming, motile, Gramnegative bacillus of family Enterobacteriaceae, having an optimum $\mathrm{pH}$ growing range between $5.0-8.0,25-37{ }^{\circ} \mathrm{C}$ for growth temperature and a low salinity toleration (below $5 \%$ ).

The strain also presented oxidase and negative catalase response (Table 2). In addition, genes for chitinase production were found in the genome. Antifungal resistance was not tested in L. adecarboxylata strain Palotina by the inoculation with Aspergillus flavus.

Halo zone formation on blood agar medium was observed in vitro, which points to hemolysin gene expression, confirming the opportunistic pathogen trait. A lipase gene was annotated in the genome, demonstrates a potential use of this strain for biotechnological purposes. Moreover, we identified genes that can be related to the improvement of nutrient availability to plants (Tables 3 and 4), which is consistent with many plant growth promoting bacteria (PGPB). The genome of $L$ adecarboxylata strain Palotina possesses genes encoding glucose dehydrogenase $(\mathrm{gcd})$, the major enzyme responsible for the production of gluconic acid. Palotina strain showed a medium capacity of $\mathrm{P}$ solubilization $(2<\mathrm{PSI}>4)$ (Table 2$)$. UDP-glucose dehydrogenase gene was present in all 16 Leclercia genomes (Table 3).

$\operatorname{Trp}$ cluster $(\operatorname{trp} C, D$ and $F)$, tryptophan-permease, tryptophan-synthase (a) and (b) genes, and indole acetamide hydrolase gene involved in tryptophan biosynthesis were found in the genome (Table 4). We observed an increase of 2.3-fold in IAA production when tryptophan was added to the culture medium (Table 2). When we compared all 16 Leclercia genomes, the phosphoribosyl anthranilate isomerase gene was found in all strains (Table 3).

\section{Subsystem Coverage}

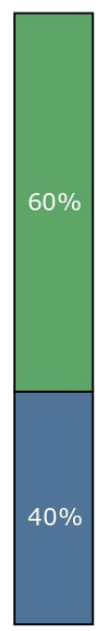

Subsystem Category Distribution

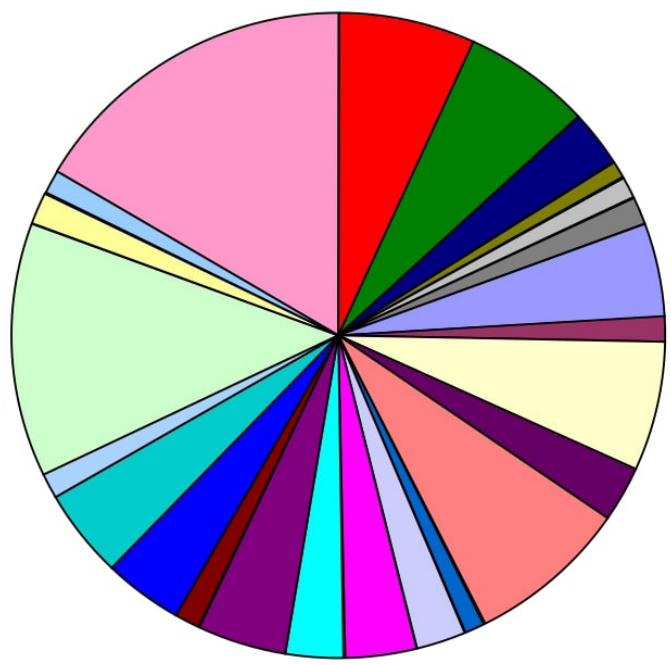

Subsystem Feature Counts

Cofactors, Vitamins, Prosthetic Groups, Pigments (269) Cell Wall and Capsule (243)

Virulence, Disease and Defense (99)

Potassium metabolism (31)

Photosynthesis (0)

Miscellaneous (51)

Phages, Prophages, Transposable Elements, Plasmids (44)

Membrane Transport (173)

Iron Acquisition and Metabolism (54)

RNA Metabolism (234)

Nucleosids and Nucleotides (114)

Protein Metabolism (234)

Cell Division and Cell Cycle (37)

Motility and Chemotaxis (96)

Regulation and Cell Signaling (133)

Secondary Metabolism (5)

Secondary Metabolism

Fatty Acids, Lipids, and Is

Fatty Acids, Lipids, and Isoprenoids (166)

Nitrogen Metabolism (49)

Dormancy and Sporulation (5)

Respiration (152)

Stress Response (169)

Metabolism of Aromatic Compounds (40)

Amino Acids and Derivates (470)

Sulfur Metabolism (60)

Phosphorus Metabolism (47)

Carbohydrates (613)

Figure 2 - Functional analyses of L adecarboxylata strain Palotina genome. 


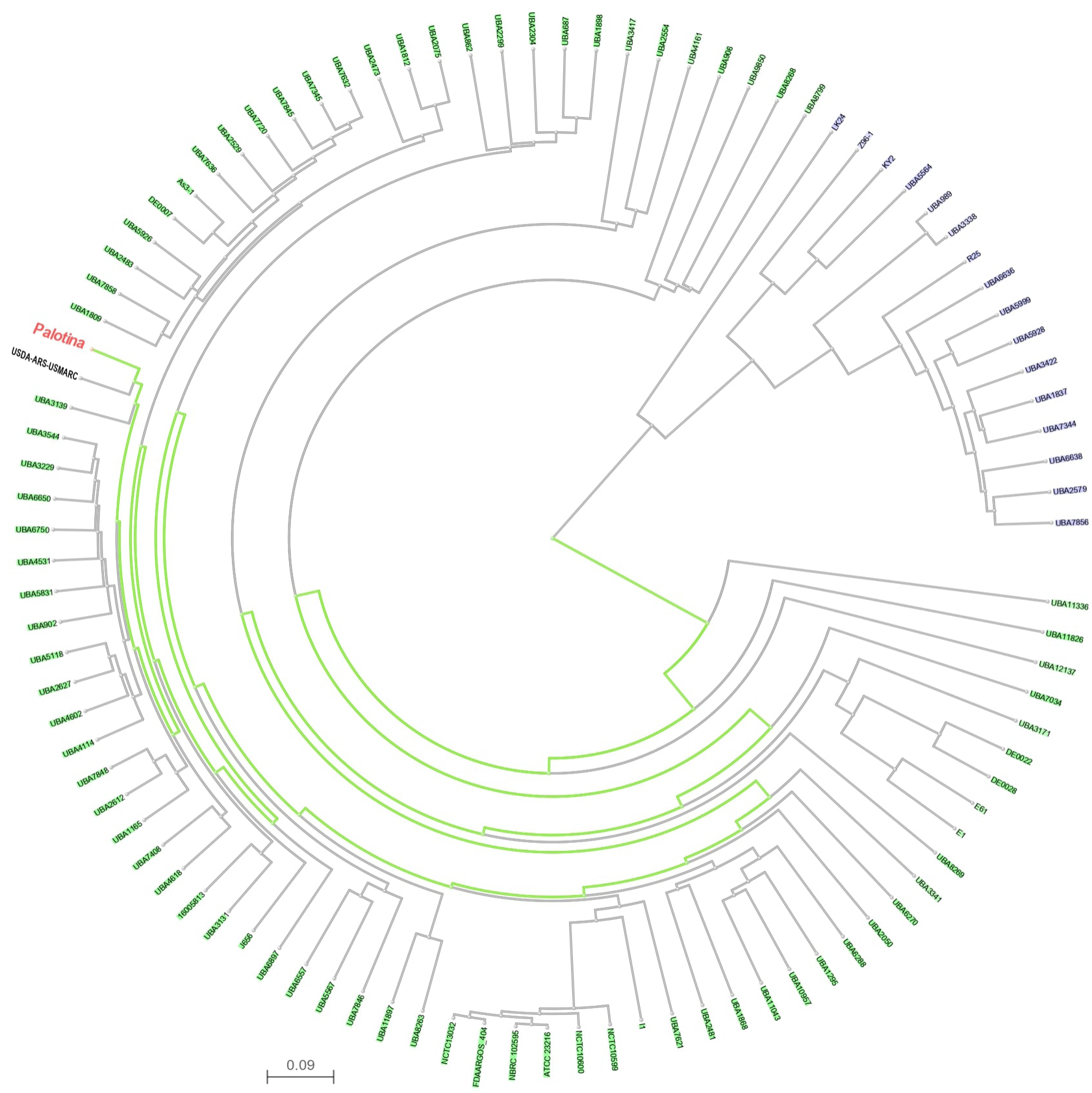

Figure 3 - Phylogenetic relationship among Leclercia strains. In red L. adecarboxylata strain Palotina. The sequences were aligned using the Neighborjoining method (Saitou and Nei, 1987). The 1,000 resampling bootstrap values are shown.

Ammonia assimilation genes, among others, seem to be the main $\mathrm{N}$ metabolism pathway, confirmed by the presence of several genes, such as GS type I (Glutamine synthase); NADPH-GOGAT; Amt (ammonia transporter); NRI (protein regulator) and $P K I I$ (Table 4).

The Ferric hydroxamate ABC transporter $F h u$ genes $F h u, V i u B, T o n B, T o n B 3, F i U$ were verified, although we did not evaluate the siderophore production (Table 4). Genes coding for antioxidant enzymes as peroxidases, catalases, superoxide dismutase, among others, were found at
L. adecarboxylata genome (Table 4). Genes that enable bacteria to survive at harsh conditions were also detected: heat shock tolerance genes (groE, YciM, hslJ, FtsJ/RrmJ), cold shock tolerance $(\operatorname{csp} A, C, D, E, G)$, and glycine betaine (Gupta et al., 2014).

Some genes related to cell-cell communication via quorum sensing (QS) were found in the L. adecarboxylata genome: N-3-oxohexanoyl-L-homoserine lactone quorumsensing transcriptional activator, Autoinducer 2 (AI-2) transport and processing (lsrACDBFGE) operon (Table 4). 
Table 2 - Biological and plant growth promotional properties of $L$. adecarboxylata strain Palotina.

\begin{tabular}{lc}
\hline & Attributes \\
\hline $\mathrm{pH}$ tolerance levels & $5.0-8.0$ \\
Optimum $\mathrm{pH}$ for growth & $6.0-7.0$ \\
$\mathrm{NaCl}$ tolerance & $<5 \%$ \\
Optimum temperature for growth & $25-37^{\circ} \mathrm{C}$ \\
IAA production & Positive $\left(2.6 \pm 0.3 \mu \mathrm{g} . \mathrm{mL}^{-1}\right)$ \\
Phosphate solubilization & Positive $\left.\left(\mathrm{PSS}^{>}\right)^{2}\right)$ \\
Oxidase & Negative \\
Catalase & Negative \\
Chitinase & Negative \\
Hemolysis & Positive
\end{tabular}

Table 3 - Plant growth promotion genes in all strains compared.

\begin{tabular}{|c|c|c|c|c|c|}
\hline \multirow[b]{2}{*}{ Organism } & \multicolumn{5}{|c|}{ Identities \% } \\
\hline & Strain & $\begin{array}{l}\text { Indoleacetamide } \\
\text { hydrolase }\end{array}$ & $\begin{array}{l}\text { UDP-glucose } \\
\text { dehydrogenase }\end{array}$ & $\begin{array}{c}\text { Phosphoribosylanthranilate } \\
\text { isomerase }\end{array}$ & Isolation source \\
\hline L. adecarboxylata & NCTC13032 & 98 & 98 & 99 & Drinking water \\
\hline L. adecarboxylata & Z96-1 & 79 & 88 & 90 & Human stool \\
\hline L. adecarboxylata & E61 & 98 & 98 & 98 & Shower \\
\hline L. adecarboxylata & P12375 & 98 & 98 & 98 & Hospital \\
\hline L. adecarboxylata & J656 & 98 & 97 & 99 & Human secretion \\
\hline L. adecarboxylata & 16005813 & 97 & 98 & 98 & Sputum \\
\hline L. adecarboxylata & USDA-ARS-USMARC-60222 & 98 & 98 & 99 & Calf nasopharynx \\
\hline L. adecarboxylata & E1 & 98 & 98 & 98 & Shower \\
\hline L. adecarboxylata & $\mathrm{R} 25$ & 87 & 92 & 91 & Rabbit \\
\hline Leclercia sp. & W6 & Not match & 88 & 90 & Human stomach \\
\hline Leclercia sp. & 119287 & 87 & 92 & 91 & Hospital \\
\hline Leclercia sp. & 1106151 & Not match & 89 & 90 & Urine \\
\hline Leclercia sp. & LSNIH1 & Not match & 89 & 90 & Sludge \\
\hline Leclercia sp. & LSNIH3 & 98 & 99 & 99 & Sludge \\
\hline Leclercia sp. & J807 & Not match & 89 & 90 & Human blood \\
\hline Leclercia sp. & W17 & Not match & 89 & 90 & Human stomach \\
\hline
\end{tabular}

Table 4 - List of genes attributable to plant growth promotion traits in L adecarboxylata genome.

\begin{tabular}{|c|c|}
\hline Plant growth promotion traits & Genes with potential for conferring PGP traits \\
\hline Phosphate solubilization & Glucose dehydrogenase gene \\
\hline IAA production & $\operatorname{TrpD}, \operatorname{Tr} p F$, tryptophan-permease, tryptophan-synthase (a) and (b), indole acetamide (Indole acetamide hydrolase) \\
\hline $\mathrm{N}$ assimilation & $G S$ type I, NaDPH-GOGAT, $A m t$, NRI, PIIK \\
\hline Siderophore production & Ferric hydroxamate ABC transporter (Fhu genes), $\operatorname{ViuB}, T o n B, T o n B 3, F i U$ \\
\hline Acetoin \& butanediol synthesis & Acetolactate synthase large subunit, Acetolactate synthase small subunit \\
\hline Phenazine production & $p h z F$ \\
\hline Chitinase production & Chitinase gene \\
\hline Trehalose metabolism & Trehalose -6-phosphate synthase gene \\
\hline Quorum sensing & $\begin{array}{l}\text { Autoinducer } 2(\mathrm{AI}-2) \text { transport and processing (lsrACDBFGE operon) } \\
\text { N-3-oxohexanoyl-L-homoserine lactone quorum-sensing transcriptional activator }\end{array}$ \\
\hline Heat shock proteins & groE, YciM, hslJ, FtsJ/RrmJ \\
\hline Cold shock proteins & $\operatorname{csp} A, C, D, E, G$ \\
\hline Glycine-betaine production & $\operatorname{proX}$ \\
\hline Peroxidases & osm $C$, glutathione peroxidase genes similar to Enterobacter asburiae \\
\hline Catalases & Catalase gene \\
\hline Superoxide dismutase & superoxide dismutase gene \\
\hline Auxins production & Monoamine oxidase, Phosphoribosyl anthranilate isomerase, Tryptophan synthase alpha and beta chain \\
\hline
\end{tabular}




\section{Discussion}

Our findings indicate the complete absence of the RND protein family, which was reported as a group of bacterial transport proteins involved in cell division, nodulation and heavy metal resistance (Nies, 2003). Another gene sequence that appeared to be distinct among Leclercia genomes is the clustered regularly interspaced short palindromic repeats (CRISPR), which is related to the microbial immune system. It contains a family of proteins whose functional domains are related to polynucleotide-binding proteins, polymerases, nucleases, and helicases (Horvath and Barrangou, 2010; Ishino et al., 2018). This region was observed in only three of Leclercia strains, including strain Palotina, which shows a horizontal gene transfer promoting a genomic differentiation among strains (Portillo and Gonzalez, 2009). A Type I restriction system or Restriction modification system (R-M system) was absent in all compared genomes. R-M system has large pentameric proteins with separate restriction, methylation and DNA sequencerecognition subunits (Loenen et al., 2014), which grants to the host bacterium a selective advantage (Sitaraman, 2016).

Carbohydrate metabolism genes were present in $L$. adecarboxylata strain Palotina enabling this bacterium to grow in different media using different carbohydrate/energy sources, including root exudates and other organic compounds. Moreover, this strain would interact positively with plants under harsh soil conditions.

Although our strain was able to carry out an alpha hemolysis, Muratoglu et al., (2009) and Anuradha (2014), who tested L. adecarboxylata Ld1 and human isolates respectively, found a negative response to blood hemolysis. The contrasting results could possibly be explained by the presence of the hemolysin gene set found in the genome of our strain.

Strain Palotina showed a P solubilization capacity, probably explained by the presence of the $g c d$ gene. Glucose dehydrogenase is the key enzyme in the biosynthesis of gluconic acid in the direct oxidation pathway of glucose, responsible for P solubilization (Chen et al., 2016; Suleman et al., 2018). The amount of gluconic acid released would control the availability of soluble phosphates (De Werra et al., 2009). Also, UDP-glucose dehydrogenase found in all compared strains (Table 3 ) catalyzes an $\mathrm{NAD}^{+}$-dependent twofold oxidation of UDP-glucose to generate UDP-glucuronic acid (Chen et al., 2019). This acid is also a precursor to UDPxylose component of the cell wall polysaccharides in plants (Gibeaut and Carpita, 1994).

Another important PGP feature is the auxins/cytokinins biosynthesis. The biosynthesis of IAA occurs from tryptophan (Patten et al., 2013) and a higher IAA production can be induced by addition of tryptophan to culture media. Biosynthesis of tryptophan encoded by trp genes occurs in five-step reactions from chorismate (Spaepen and Vanderleyden, 2011). Five different pathways were described to the IAA production in bacteria: the indole-3-acetamide (IAM), indole-3-pyruvic acid (IPyA), indole-3-acetonitrile (IAN), tryptamine (TAM), and tryptophan side-chain oxidase (TSO) pathways (Kochar et al., 2013; Li et al., 2018).

Genomic analyses identified the indole acetamide hydrolase gene, which explains the IAA production mainly by IAM pathway suggesting the tryptophan-dependent IAM pathway function in strain Palotina. The main pathway to IAA production in PGPB is via indole-3-pyruvic acid, dependent on L-tryptophan (Souza et al., 2015). Not all Leclercia adecarboxylata and no Leclercia sp. strains present the indole acetamide hydrolase gene, which suggests that this gene has been acquired. This fact explains the association between bacteria and corn plants.

In addition, we identified the sequence of phosphoribosyl anthranilate isomerase (PRAI) encoded by $\operatorname{trpC}$ (Table 4). This enzyme is responsible for the conversion of $\mathrm{N}-\left(5^{\prime}\right.$-phosphoribosyl)-anthranilate (PRA) to 1-(o-carboxyphenylamino)-1-deoxyribulose 5-phosphate (CdRP), the fourth step in tryptophan biosynthesis (Thoma et al., 2000). Moreover, monoamine oxidase plays an important role in tryptamine biosynthesis, whose oxidative deamination of tryptamine to indole acetaldehyde is known to be the main course for IAA formation, despite the fact that the role of monoamine oxidase has not been completely characterized (Ueno et al., 2003). The presence of these genes suggests that the tryptophan-dependent IAM and TAM pathways function in L. adecarboxylata.

$L$ adecarboxylata produced $2.6 \mu \mathrm{g} \cdot \mathrm{mL}^{-1}$ of IAA(Table 2). Albeit the variable levels, Gupta et al., (2014) related IAA production of 1.2-2.5 ug. $\mathrm{mL}^{-1}$ to candidate PGPB strains isolated from coconut, cocoa and arecanut plants, while Moreira et al., (2016) found strains that could produce more than $80 \mu \mathrm{g} \cdot \mathrm{mL}^{-1}$ of indolic compounds. We did not identify an acdS gene coding for ACC deaminase enzyme in our strain, which demonstrates the absence of this enzyme among PGP traits. However, Kang et al. (2019) suggested that the IAA and ACC deaminase helped tomato (Solanum lycopersicum) plants to tolerate salt stress, despite having found $a c d S$ gene in L. adecarboxylata strain MO1.

Ammonia assimilation, among others, seems to be the main $\mathrm{N}$ metabolization pathway from nitrate. In addition, this strain exhibits the genes for denitrification used as energy source. These genes indicated that $L$. adecarboxylata has an important role in soil $\mathrm{N}$ cycling system. The results agree with Muratoglu et al. (2009) who observed an absence of nitrogen fixation capacity as well as a presence of $\mathrm{NO}_{2}$ metabolism in Ld1 strain. From these data, L. adecarboxylata can be used as a model for PGP bacteria exclusively by auxins production.

Peroxidases, catalases, superoxide dismutase, and glutathione transferases genes found at $L$. adecarboxylata genome could help plants to overcome oxidative stress. Also, heat and cold shock genes could support bacteria to survive during abiotic or biotic stress (Gupta et al., 2014), which enable bacteria to adapt to adverse growth conditions.

Another strategy to copy with abiotic stresses is the accumulation of compatible solutes, such as trehalose, proline and glycine betaine, among others, by some soil bacteria (Suarez et al., 2019). The strain Palotina genome contains trehalose-6-phosphate synthase involved in GDP- or UDPglucose conversion to trehalose (Avonce et al., 2006). Also, glycine betaine/proline betaine-binding periplasmic protein $($ ProX $)$ is one of three genes from operon $V W X$ involved in binding compatible solutes with high affinity and specificity (Schiefner et al., 2004). 
We also found genes related to acetoin and 2,3 butanediol production, which are volatile compounds (VOCs) involved in plant growth bacteria/fungi interaction as acetolactate synthase large and small subunit (Yi et al., 2016; Fincheira and Quiroz, 2018). VOCs are synthesized by the condensation of two pyruvate molecules into acetolactate by acetolactate synthase, which forms acetoin by acetolactate decarboxylase decarboxylation. The reduction of acetoin by acetoin reductase results in 2,3-butanediol (Suarez et al., 2019).

The strain Palotina contains $p h z F$ encoding phenazine biosynthesis. Phenazines can modify the cellular redox state by electron transport, acting in the cell signaling regulating gene expression. By contributing to biofilm formation and architecture, it can enhance bacterial viability in the rhizosphere (Pierson and Pierson, 2010).

Autoinducer 2 (AI-2) transport and processing (lsrACDBFGE) operon (Table 4) codifies molecules related to motility, biofilm formation and production of virulence factors (Reading and Sperandio, 2006). AI-2 has been suggested to act directly through quorum sensing while (lsrACDBFGE) operon encodes an ATP-binding cassette transporter (ABC transporter) that internalizes AI-2 in gram-negative bacteria (Papenfort and Bassler, 2014). In the marine bacterium Vibrio fischeri, N-(3-oxo-hexanoyl)-L-homoserine lactone (3-oxo-C6-HSL) acts as autoinducer in the quorum-sensing system (Yan et al., 2007).

Genome sequencing of a strain might provide more abundant screening tools for the PGPB, which could be readily detected in genomes (Finkel et al., 2017). The authors mentioned that the presence of minimal Nif cluster and genes required for indole acetic acid production are potent markers, albeit at variable levels, for screening potential strains, making the process faster and less labor extensive. Scagliola et al. (2016) affirmed that a potential PGPB candidate must have the ability to solubilize phosphate and iron (siderophores) and IAA. The data pointed to a PGP strain candidate and further studies should be conducted to reveal the full genetic mechanisms of plant interaction.

\section{Acknowledgments}

We would like to thank CAPES (Coordenação de Aperfeiçoamento de Pessoal de Nível Superior) for supplying scholarship for the first author. We are grateful to Eduardo Balsanelli and Valter Baura for the genome sequencing. Also, thanks to the Academic Publishing Advisory Center (Centro de Assessoria de Publicação Acadêmica, CAPA - www.capa. ufpr.br) of the Federal University of Paraná for assistance with English language editing.

\section{Conflict of Interest}

The authors declare that there is no conflict of interest.

\section{Author Contributions}

ECGV conceived the project and wrote the manuscript. AS and AF conducted the laboratory experiments. DM performed the genomics data analysis. MFS did the corrections.

\section{References}

Alikhan NF, Petty NK, Ben Zakour NL and Beatson SA (2011) BLAST Ring Image Generator (BRIG): Simple prokaryote genome comparisons. BMC Genomics 12:402.

Altschul SF, Gish W, Miller W, Myers EW and Lipman DJ (1990) Basic local alignment search tool. J Mol Biol 215:403-410.

Anuradha M (2014) Leclercia adecarboxylata isolation: Case reports and review. J Clin Diagnostic Res 8:DD03-DD04.

Avonce N, Mendoza-Vargas A, Morett E and Iturriaga G (2006). Insights on the evolution of trehalose biosynthesis. BMC Evolut Biol 6:109.

Aziz RK, Bartels D, Best AA, DeJongh M, Disz T, Edwards RA, Formsma K, Gerdes S, Glass EM, Meyer F, et al. (2008) The RAST Server: Rapid Annotations using Subsystems Technology. BMC Genomics 9:75.

Bankevich A, Nurk S, Kulikov AS, Prjibelski AD, Tesler G, Vyahhi N, Sirotkin A V., Pham S, Dvorkin M, Nikolenko SI, et al. (2012) SPAdes: A new genome assembly algorithm and its application to single-cell sequencing. J Comput Biol 19:455-477.

Beneduzi A, Ambrosini A and Passaglia LMP (2012) Plant growthpromoting rhizobacteria (PGPR): Their potential as antagonists and biocontrol agents. Genet Mol Biol 35:1044-51.

Chaves EID, Guimarães VF, Vendruscolo ECG, dos Santos MF, de Oliveira FF, de Abreu JAC, Camargo MP, Schneider VS, de Souza EM, Cruz LM, et al. (2019) Interactions between endophytic bacteria and their effects on poaceae growth performance in different inoculation and fertilization conditions. Aust J Crop Sci 13:69-79.

Chen L, Shi H, Heng J, Wang D and Bian K (2019) Antimicrobial, plant growth-promoting and genomic properties of the peanut endophyte Bacillus velezensis LDO2. Microbiol Res 218:41-48.

Chen W, Yang F, Zhang L and Wang J (2016) Organic acid secretion and phosphate solubilizing efficiency of Pseudomonas sp. PSB12: Effects of phosphorus forms and carbon sources. Geomicrobiol J 33:870-877.

Choudhary M, Choudhary BK, Bhoyar S, Kale SB, Chaudhari SP, Bera BC, Jain A and Barbuddhe SB (2018) Isolation and characterization of multidrug-resistant Leclercia species from animal clinical case. Lett Appl Microbiol 66:44-48.

Cruz LM, Souza EM, Weber OB, Dobereiner J, Baldani JI and Pedrosa O (2001) 16S Ribosomal DNA characterization of nitrogen-fixing bacteria isolated from banana (Musa spp.) and pineapple (Ananas comosus (L) Merril). Appl Environ Microbiol 67:2375-2379.

De Werra P, Péchy-Tarr M, Keel C and Maurhofer M (2009) Role of gluconic acid production in the regulation of biocontrol traits of Pseudomonas fluorescens CHA0. Appl Environ Microbiol 75:4162-4174.

Dobereiner J, Baldani VLD and Baldani JI (1995) Como isolar e identificar bactérias diazotróficas de plantas não-leguminosas. EMBRAPA-SPI, Brasília, DF; EMBRAPA-CNPAB, Itaguaí, $60 \mathrm{p}$.

Fincheira P and Quiroz A (2018) Microbial volatiles as plant growth inducers. Microbiol Res 208:63-75.

Finkel OM, Castrilho G, Paredes SH, Gonzales I and Dangl JL (2017) Understanding and exploiting plant beneficial microbes. Curr Opin Plant Biol 28:155-163.

Gibeaut DM and Carpita NC (1994) Biosynthesis of plant cell wall polysaccharides. FASEB J 8:904-915.

Glickmann E and Dessaux Y (1995) A critical examination of the specificity of the Salkowski reagent for indolic compounds produced by phytopathogenic bacteria. Appl Environ Microbiol 61:793-796. 
Gupta A, Gopal M, Thomas GV, Manikandan V, Gajewski J, Thomas G, Seshagiri S, Schuster SC, Rajesh P and Gupta R (2014) Whole genome sequencing and analysis of plant growth promoting bacteria isolated from the rhizosphere of plantation crops coconut, cocoa and arecanut. PLoS One 9:e104259.

Horvath P and Barrangou R (2010) CRISPR/Cas, the immune system of Bacteria and Archaea. Science 327:167-170.

Hoyos-Mallecot Y, Rojo-Martín María Dolores, Bonnin RA, Creton E, Marí JMN and Naasa T (2017) Draft genome sequence of NDM-1- producing Leclercia adecarboxylata. Genome Announc 5:177-178.

Ishino Y, Krupovic M and Forterre P (2018) History of CRISPR-Cas from encounter with a mysterious. J Bacteriol 200:e00580-17.

Jha CK and Saraf G (2015) Plant growth-promoting Rhizobacteria: A critical review. J Agric Res Dev 5:108-119.

Kang SM, Shazad R, Bilal S, Khan AL, Park YG, Lee KE, Asaf S, Khan MA and Lee IJ (2019) Indole-3-acetic-acid and ACC deaminase producing Leclercia adecarboxylata $\mathrm{MO} 1$ improves Solanum lycopersicum L. growth and salinity stress tolerance by endogenous secondary metabolites regulation. BMC Microbiol 19:80.

Kashani A, Chitsazan M, Che K and Garrison RC (2014) Leclercia adecarboxylata bacteremia in a patient with ulcerative colitis. Case Rep Gastrointest Med 2014:1-4.

Kochar M, Vaishnavi A, Upadhyay A and Srivastava S (2013) Bacterial biosynthesis of indole-3-acetic acid: signal messenger service. Mol Microb Ecol Rhizosph 1:309-325.

Kovacks N (1956) Identification of Pseudomonas pyocyanea by the oxidase reaction. Nature 178:703.

Laili NS, Othman R and Razarah SS (2017) Isolation and characterization of plant growth-promoting rhizobacteria (PGPR) and their effects on growth of strawberry (Fragaria Ananassa Duch.). Bangladesh J Bot 46:277-282.

Leclerc H (1962) Biochemical study of pigmented Enterobacteriaceae. Ann Inst Pasteur (Paris) 102:726-741.

Li M, Guo R, Yu F, Chen X, Zhao H, Li H and Wu J (2018) Indole3 -acetic acid biosynthesis pathways in the plant-beneficial bacterium Arthrobacter pascens zz21. Int J Mol Sci 19:443.

Loenen WAM, Dryden DTF, Raleigh EA and Wilson GG (2014) Type I restriction enzymes and their relatives. Nucleic Acids Res 42:20-44.

Moreira FS, Costa PB, Souza R De, Beneduzi A, Lisboa BB, Vargas LK and Passaglia LMP (2016) Functional abilities of cultivable plant growth promoting bacteria associated with wheat (Triticum aestivum L.) crops. Genet Mol Biol 39:111-121.

Muratoglu H, Kati H, Demirbag Z and Sezen K (2009) High insecticidal activity of Leclercia adecarboxylata isolated from Leptinotarsa decemlineata (Col.: Chrysomelidae). J Biotechnol 8:7111-7115.

Nautiyal CS (1999) An efficient microbiological growth medium for screening phosphate solubilizing microorganisms. FEMS Microbiol Lett 170:265-270.

Nautiyal CS, Bhadauria S, Kumar P, Lal H and Mondal R (2000) Stress induced phosphate solubilization in bacteria isolated from alkaline soils. FEMS Microbiol Lett 182:291-296.

Nies DH (2003) Efflux-mediated heavy metal resistance in prokaryotes. FEMS Microbiol Rev 27:313-339.

Papenfort K and Bassler B (2014) Quorum-sensing signal-response systems in Gram-negative bacteria. Nat Rev Microbiol 9:91108.

Patten CL, Blakney AJC and Coulson TJD (2013) Activity, distribution and function of indole-3-acetic acid biosynthetic pathways in bacteria. Crit Rev Microbiol 39:395-415.
Pierson LS and Pierson EA (2010) Metabolism and function of phenazines in bacteria: impacts on the behavior of bacteria in the environment and biotechnological processes. Appl Microbiol Biotechnol 86:1659-1670.

Portillo MC and Gonzalez JM (2009) CRISPR elements in the Thermococcales: Evidence for associated horizontal gene transfer in Pyrococcus furiosus. J Appl Genet 50:421-430.

Reading NC and Sperandio V (2006) Quorum sensing: The many languages of bacteria. FEMS Microbiol Lett 254:1-11.

Russell FM, Biribo SSN, Selvaraj G, Oppedisano F, Warren S, Seduadua A, Mulholland EK and Carapetis JR (2006) As a bacterial culture medium, citrated sheep blood agar is a practical alternative to citrated human blood agar in laboratories of developing countries. J Clin Microbiol 44:3346-3351.

Saitou N and Nei M (1987) The neighbor-joining method: a new method for reconstructing phylogenetic trees. Mol Biol Evol 4:406-425.

Sarwar M and Kremer RJ (1995) Determination of bacterially derived auxins using a microplate method. Lett Appl Microbiol 20:282-285.

Scagliola M, Pii Y, Mimmo T, Cesco S, Ricciuti P and Crecchio C (2016) Characterization of plant growth promoting traits of bacterial isolates from the rhizosphere of barley (Hordeum vulgare L.) and tomato (Solanum lycopersicon L.) grown under Fe sufficiency and deficiency. Plant Physiol Biochem 107:187-196.

Schiefner A, Breed J, Bösser L, Kneip S, Gade J, Holtmann G, Diederichs K, Welte W and Bremer E (2004) Cation-pi interactions as determinants for binding of the compatible solutes glycine betaine and proline betaine by the periplasmic ligand-binding protein ProX from Escherichia coli. J Biol Chem 279: 5588-5596.

Sitaraman R (2016) The role of DNA restriction-modification systems in the biology of Bacillus anthracis. Front Microbiol 7:11.

Souza R de, Ambrosini A and Passaglia LMP (2015) Plant growthpromoting bacteria as inoculants in agricultural soils. Genet Mol Biol 38:401-419.

Souza EM, Funayama S, Rigo LU and Pedrosa FDO (1991) Cloning and characterization of the nif A gene from Herbaspirillurn seropedicae strain Z78. Can J Microbiol 37:425-429.

Spaepen S and Vanderleyden J (2011) Auxin and plant-microbe interactions. Cold Spring Harb Perspect Biol 3:1-13.

Suarez C, Ratering S, Hain T, Fritzenwanker M, Goesmann A, Blom J, Chakraborty T, Bunk B, Spröer C, Overmann J, et al. (2019) genome sequence of the plant growth-promoting bacterium Hartmannibacter diazotrophicus Strain E19 ${ }^{\mathrm{T}}$. Int J Genomics. 2019:7586430.

Suleman M, Yasmin S, Rasul M, Yahya M, Atta BM and Mirza MS (2018) Phosphate solubilizing bacteria with glucose dehydrogenase gene for phosphorus uptake and beneficial effects on wheat. PLoS One 13:1-28.

Tamura K, Sakazaki R, Kosako Y and Yoshizaki E (1986) Leclercia adecarboxylata Gen. Nov., Comb. Nov., formerly known as Escherichia adecarboxylata. Curr Microbiol 13:179-184.

Thoma R, Hennig M, Sterner R and Kirschner K (2000) Structure and function of mutationally generated monomers of dimeric phosphoribosylanthranilate isomerase from Thermotoga maritima. Structure 8:265-276.

Ueno M, Shibata H, Kihara J, Honda Y and Arase S (2003) Increased tryptophan decarboxylase and monoamine oxidase activities induce Sekiguchi lesion formation in rice infected with Magnaporthe grisea. Plant J 36:215-228. 
Yan L, Allen MS, Simpson ML, Sayler GS and Cox CD (2007) $\mathrm{N}$-(3-oxo-hexanoyl)-L-homoserine lactone (3-oxo-C6-HSL) plays a significant role as autoinducer in the quorum-sensing system. J Microbiol Methods 68:40-45.

Yano DMY, Attili DS, V GMS, Eguchi SY and Oliveira UM (1991) Técnicas de microbiologia em controle de qualidade. Fundação Tropical de Pesquisa e Tecnologia André Tosello, Campinas. Yi HS, Ahn YR, Song GC, Ghim SY, Lee S, Lee G and Ryu CM (2016) Impact of a bacterial volatile 2,3-butanediol on Bacillus subtilis rhizosphere robustness. Front Microbiol 7:1-11.

\section{Supplementary Material}

The following online material is available for this article: Table S1 - List of genes and their function in L. adecarboxylata strain Palotina.
Table S2 - List of genes related to plant growth promotion in L. adecarboxylata strain Palotina.

Figure S1 - Genomic map of CRISPR system.

Figure S2 - Genomic map of RND efflux system.

Figure S3 - Genomic map of Type I restriction-modification system.

License information: This is an open-access article distributed under the terms of the Creative Commons Attribution License (type CC-BY), which permits unrestricted use, distribution and reproduction in any medium, provided the original article is properly cited. 